\title{
Medial frontal cortex function: An introduction and overview
}

\author{
K. RICHARD RIDDERINKHOF \\ University of Amsterdam, Amsterdam, The Netherlands \\ SANDER NiEUWENHUIS \\ Leiden University, Leiden, The Netherlands \\ AND \\ TODd S. BRAVER \\ Washington University, St. Louis, Missouri
}

\begin{abstract}
The growing attention being given to medial frontal cortex (MFC) in cognitive neuroscience studies has fostered a number of theoretical and paradigmatic perspectives that diverge in important ways. This has led to a great deal of research fractionation, with investigators studying domains and issues in MFC function that sometimes bear (at least at the surface) little relation to the questions addressed by others studying the same brain region. The present issue of Cognitive, Affective, \& Behavioral Neuroscience presents articles inspired by a conference bringing together views from across this diversity of research, highlighting both the richness and vibrancy of the field and the challenges to be faced in terms of integration, synthesis, and precision among the theoretical accounts. The present article presents a brief introduction, overview, and road map to the field and to the special issue devoted to MFC function.
\end{abstract}

\section{May you live in interesting times.}

The quotation above is attributed to an ancient Chinese proverb that can either be used as a curse or a blessing. ${ }^{1}$ Indeed, both senses seem to apply well to the explosion of research conducted on medial frontal cortex (MFC) function in the last decade. Investigators studying these issues (such as ourselves) can certainly be gratified by the growing database of findings and the growing sophistication of theoretical models being put forward. Nevertheless, the downside of this embarrassment of riches in data, phenomena, and theory is that it has become harder and harder to integrate and synthesize the literature. Moreover, the growing attention being given to MFC in cognitive neuroscience studies has led to a great deal of research fractionation, with many investigators studying domains and issues in MFC function that seem to bear (at least at the surface) little relation to the questions addressed by other researchers studying the same brain region. It is the assessment of this state of affairs that started the chain of events that led to this special issue of Cognitive, Affective, \& Behavioral Neuroscience (CABN). But before describing the chronology of these events, it is worth providing a bit more historical context, in order to better appreciate how far the field has come in the last decade.

\section{History of Research on MFC Function}

It is clearly the case that much of the theoretical and conceptual core of the work presented in this special issue arises from trends present in the older literature, such as neuropsychological work emphasizing the roles of MFC and anterior cingulate cortex (ACC) in evaluating the motivational dimensions of attention (Mesulam, 1981) and action (Damasio \& Van Hoesen, 1983), neurophysiological studies reporting the involvement of this region in the detection of errors (Gemba, Sasaki, \& Brooks, 1986; Niki \& Watanabe, 1979) and in learning from aversive outcomes (Gabriel, 1993), and cognitive theories implicating ACC in executive functions (Vogt, Finch, \& Olson, 1992) and response selection (Posner \& Petersen, 1990). Yet it is fair to say that much of the current research on MFC/ACC function was spawned by two distinct streams of human cognitive neuroscience research occurring in the 1990s: (1) event-related-potential (ERP) studies of error detection and compensation focusing on the so-called ERN/Ne component (Falkenstein, Hohnsbein, \& Hoormann, 1991; Gehring, Goss, Coles, Meyer, \& Donchin, 1993) and (2) neuroimaging studies of cognitively demanding tasks, such as the Stroop, go/no-go, and verb generation/verbal fluency tasks, that have demonstrated reliable activation of the MFC/ACC (Cabeza \& Nyberg, 1997; Paus, Koski, Caramanos, \& Westbury, 1998). These two streams converged in a study by Carter et al. (1998), which showed that the same region of ACC was activated both by overt errors and by trials associated with high response conflict. This initial finding culminated in the development of conflictmonitoring theory, a computationally explicit account of

K. R. Ridderinkhof, k.r.ridderinkhof@uva.nl 
the role of ACC in cognitive control that attempted to integrate and synthesize the extant ERP and neuroimaging data (Botvinick, Braver, Barch, Carter, \& Cohen, 2001).

Yet science as always marches on, and since that point, not only have there been advances (Yeung, Botvinick, \& Cohen, 2004) and refinements (Brown \& Braver, 2005) to the conflict-monitoring model, but a range of welldeveloped competing computational accounts (Holroyd \& Coles, 2002; Holroyd, Yeung, Coles, \& Cohen, 2005) and alternative theoretical proposals (Rushworth, Walton, Kennerley, \& Bannerman, 2004) have also been put forward. Moreover, the initial interest in the processes underlying error detection and compensation has developed into a more broadly based study of the whole class of performance-monitoring phenomena and mechanisms. These include additional ERP components of interest (e.g., N2, Pe, and EPP; Nieuwenhuis, Yeung, van den Wildenberg, \& Ridderinkhof, 2003; Overbeek, Nieuwenhuis, \& Ridderinkhof, 2005; Ridderinkhof, Nieuwenhuis, $\&$ Bashore, 2003; Yeung et al., 2004) and a set of sequential modulations of behavior termed conflict and error adaptation effects (Botvinick et al., 2001; Mayr, Awh, \& Laurey, 2003). Likewise, there has been renewed interest not only in studying these phenomena using ERP and neuroimaging methods in healthy humans, but also in the examination of clinical and neuropsychological populations (Fellows \& Farah, 2005; Swick \& Turken, 2002) and in neurophysiological studies of nonhuman animals (Ito, Stuphorn, Brown, \& Schall, 2003; Shima \& Tanji, 1998). This work has, in many cases, injected further controversy and debate within the literature, because the results have not often conformed well with the predictions made from conflict-monitoring theory. Similarly, the increased attention to the functional neuroanatomy of the MFC region has also led to controversy and debate, resulting in the popularization of new terminological schemes (e.g., the rostral cingulate zone [Ridderinkhof, Ullsperger, Crone, \& Nieuwenhuis, 2004] and anterior rostral MFC [Amodio \& Frith, 2006]) and in claims of nearby, but functionally dissociable, anatomical subregions (e.g., ventral vs. dorsal MFC, supplementary eye field/presupplementary motor area [SEF/preSMA; Nachev, 2006; Stuphorn, Taylor, \& Schall, 2000]). ${ }^{2}$ Finally, there has been a clear broadening of the domain of studies examined by researchers interested in MFC, with a great number of current investigations focused on issues related to both decision-making (Volz, Schubotz, \& von Cramon, 2006) and social cognition (Amodio \& Frith, 2006). A common theme in this work has been a return of focus to the importance of motivational, reinforcement, and affective variables in understanding the nature of MFC function.

\section{Motivation for the Special Issue}

As the discussion above makes clear, researchers trying to make sense of the current literature on MFC function are likely to find this task quite daunting, when faced with the proliferation of research domains, methodologies, relevant empirical phenomena, theoretical accounts, and controversies that mark the field. Indeed, we faced a sense of growing unease ourselves regarding whether it was even possible any more to achieve synthesis, integration, or a unifying account. As a result, two of us (Ridderinkhof and Nieuwenhuis, along with Rogier Mars) organized a conference in Amsterdam in June $2006^{3}$ that brought researchers studying various aspects of MFC function together, with a mission to challenge each other regarding some of the key issues and questions that face the field.

A first goal was to survey the growing number of research domains and empirical phenomena being examined in terms of the role played by MFC. Although a considerable portion of MFC research is still focused on issues related to performance monitoring, even within this domain there remains a great deal of controversy as to whether the MFC should be primarily thought of as being involved in conflict monitoring or error monitoring. Is there evidence that can help resolve this controversy? A somewhat independent but related issue concerns the effects of errors and/or conflict on subsequent behavior and processing. To what degree is MFC activity directly causally involved in cognitive adaptations that lead to observable changes in performance (e.g., speed-accuracy trade-offs, shifts in attentional bias, etc.)? A broader issue concerns the fact that a growing number of studies are focusing on MFC involvement in domains that appear to be somewhat distinct from performance monitoring, including work on reinforcement learning/reward processing, decision-making, and social cognition. Can work from these domains make contact with ideas regarding MFC involvement in performance-monitoring functions? For example, a potential point of overlap is that in both the performance-monitoring studies and the studies in other domains, a key variable of interest has been the role of various forms of feedback information (not only whether or not an error was made, but also the degree of "badness" or "goodness" of the outcome) and how it was communicated (e.g., with reinforcers or via a social means).

A second goal was to address issues regarding potential discrepancies related to the methods, species, or particular anatomical regions being examined or utilized. In particular, the work from human neuroimaging and scalp electrophysiological studies often seems at variance with the literature arising from animal lesion or single-cell recording studies. Is this a matter of difference in MFC function across species, or of other issues related to the different natures of the studies being conducted or of the types of data being acquired? Furthermore, is it possible that the discrepancies between studies and species reflect functional subdivisions between nearby but potentially distinct regions of MFC, such as between ACC and SEF/preSMA or between dorsal and ventral MFC? Likewise, are there new or potential future studies that bridge the gap between methods (e.g., intracranial ERP studies in humans, monkey fMRI, and recordings of local field potentials, as well as neuronal spiking activity) that might provide some degree of resolution to this issue? In other words, what might be profitable methodological directions for new research?

A final goal was to examine and compare more critically the multitude of theoretical accounts of MFC function being put forward in the literature. In brief, some of the most well-known accounts are (1) conflict monitor- 
ing, which suggests that MFC serves as an online detector of information processing conflict (particularly between competing responses) and propagates this information to other systems (e.g., lateral PFC) that implement adjustments in cognitive control (Botvinick, Cohen, \& Carter, 2004); (2) outcome evaluation, which emphasizes the role of negative reinforcement signals in driving learning within MFC about actions that produce poor outcomes (Holroyd \& Coles, 2002); (3) risk prediction/error avoidance, in which MFC activity represents a more generic prediction of risk or error in a current situation for promoting actions that lead to avoidance of these outcomes (Brown \& Braver, 2005; Magno, Foxe, Molholm, Robertson, \& Garavan, 2006; Ridderinkhof, van den Wildenberg, Segalowitz, \& Carter, 2004); (4) cost-benefit analysis, which focuses on the role of MFC in action selection and decision-making through the estimation of both positive and negative outcome values based on reinforcement history (Rushworth, Buckley, Behrens, Walton, \& Bannerman, 2007); and (5) regulative control, which argues for a more direct implementational role for MFC in action selection, as well as regulation of affective and physiological (e.g., pain, autonomic) signals (Critchley et al., 2003; Matsumoto, Suzuki, \& Tanaka, 2003; Posner \& DiGirolamo, 1998; Roelofs, van Turennout, \& Coles, 2006; Stuphorn \& Schall, 2006). The key question for theorists and investigators is what are the specific points of contention and competition between these theories, or are they (at least to some extent) complementary? If points of contention exist among theories, are there specific data or experiments that could adjudicate between them?

The conference was undoubtedly a success, in that the juxtaposition of presentations by speakers working from various perspectives and methods caused conference participants to confront both their own preexisting ideas and the range and diversity of the extant data. Moreover, the presentations frequently produced a lively and stimulating debate, often followed by very productive interchanges that caused participants to reexamine their own views, seek consensus on points of agreement, and pull into sharper focus areas of disagreement. Although the conference obviously couldn't serve to successfully resolve all of the critical questions and areas of controversy, it did clearly demonstrate the richness and vibrancy of the current state of research, as well as highlight the challenges that remain to be faced in terms of integration, synthesis, and precision among theoretical accounts. However, the most important outcome of the conference was the sentiment that this sense of the field would be most helpful if it was disseminated to the broader community, beyond just the attendees of the conference. It was this sentiment that led to the idea of this special issue, which brings together contributions from some of the presenters at the conference, as well as from other investigative teams working on relevant questions related to MFC function.

\section{Road Map to the Special Issue}

This special issue was organized across three dimensions. First, the contributions include both novel and empirical studies (from Brown \& Braver, 2007; de Bruijn,
Schubotz, \& Ullsperger, 2007; Forstmann, Ridderinkhof, Kaiser, \& Bledowski, 2007; Frank, D'Lauro, \& Curran, 2007; Harris, McClure, van den Bos, Cohen, \& Fiske, 2007; Hester, Barre, Mattingley, Foxe, \& Garavan, 2007; Sallet et al., 2007; van den Bos, McClure, Harris, Fiske, \& Cohen, 2007; and Yeung, Ralph, \& Nieuwenhuis, 2007), as well as theoretical reviews and conceptual analyses (from Botvinick, 2007; Egner, 2007; Posner, Rothbart, Sheese, \& Tang, 2007; Schall \& Boucher, 2007; Carter \& van Veen, 2007; and Walton \& Mars, 2007). Second, the contributors include both senior, established investigators who are some of the most influential voices on MFC function (e.g., Carter, Cohen, Posner, Schall), as well as younger "rising stars" of the field who are engaging in novel, cutting-edge research (e.g., Brown, Egner, Forstmann, Frank, Hester, Mars, Walton, Yeung). Third, as described below, the contributions reflect the diversity of the perspectives, methods, and research domains that represent the current state of MFC research. All of the contributions in this special edition were invited, but each was fully peer-reviewed so as to meet the high standards of $C A B N$.

We are pleased that the work in this special issue includes perspectives and findings stemming not only from human studies, but also from animal research (see Sallet et al., 2007; Schall \& Boucher, 2007; Walton \& Mars, 2007). Moreover, the human-focused contributions comprise studies utilizing both neuroimaging (Brown \& Braver, 2007; Harris et al., 2007; Hester et al., 2007; van den Bos et al., 2007) and ERP (de Bruijn et al., 2007; Forstmann et al., 2007; Frank et al., 2007; Yeung et al., 2007) methods. Furthermore, a variety of research domains and topics are covered, from studies focusing on issues of error processing (Brown \& Braver, 2007; de Bruijn et al., 2007; Frank et al., 2007; Hester et al., 2007) and conflictmonitoring/adaptation effects (Egner, 2007; Yeung et al., 2007), to work examining decision-making/choice selection (Forstmann et al., 2007; Walton \& Mars, 2007) and reward processing (Sallet et al., 2007), to studies within the domain of social neuroscience (Harris et al., 2007; van den Bos et al., 2007). Finally, many of the studies touch on topics that are becoming more prominent in the literature on MFC function, such as individual differences (Brown \& Braver, 2007) and genetic approaches (Frank et al., 2007), the use of naturalistic tasks (de Bruijn et al., 2007; Walton \& Mars, 2007), affective valence manipulations (Harris et al., 2007; van den Bos et al., 2007), and developmental data (Posner et al., 2007). In short, we believe that the work presented here provides a nicely representative snapshot of the current state, and state of the art, of this field. The process of compiling this set of articles for the special issue has been enormously stimulating and informative to us as guest editors. We hope and trust that readers will agree that the articles in this issue make a significant contribution to the cognitive neuroscience literature on the role of MFC in the adaptive control of behavior.

\section{REFERENCES}

Amodio, D. M., \& Frith, C. D. (2006). Meeting of minds: The medial frontal cortex and social cognition. Nature Reviews Neuroscience, 7, 268-277. 
Botvinick, M. M. (2007). Conflict monitoring and decision making: Reconciling two perspectives on anterior cingulate function. Cognitive, Affective, \& Behavioral Neuroscience, 7, 356-366.

Botvinick, M. M., Braver, T. S., Barch, D. M., Carter, C. S., \& Cohen, J. D. (2001). Conflict monitoring and cognitive control. Psychological Review, 108, 624-652.

Botvinick, M. M., Cohen, J. D., \& Carter, C. S. (2004). Conflict monitoring and anterior cingulate cortex: An update. Trends in Cognitive Sciences, 8, 539-546.

Brown, J. W., \& BraVER, T. S. (2005). Learned predictions of error likelihood in the anterior cingulate cortex. Science, 307, 1118-1121.

Brown, J. W., \& Braver, T. S. (2007). Risk prediction and aversion by anterior cingulate cortex. Cognitive, Affective, \& Behavioral Neuroscience, 7, 266-277.

CABEZA, R., \& Nyberg, L. (1997). Imaging cognition: An empirical review of PET studies with normal subjects. Journal of Cognitive Neuroscience, 9, 1-26.

Carter, C. S., Braver, T. S., Barch, D. M., Botvinick, M., Noll, D., \& Cohen, J. D. (1998). Anterior cingulate cortex, error detection, and the online monitoring of performance. Science, 280, 747-749.

Carter, C. S., \& VAN Veen, V. (2007). Anterior cingulate cortex and conflict detection: An update of theory and data. Cognitive, Affective, \& Behavioral Neuroscience, 7, 367-379.

Critchley, H. D., Mathias, C. J., Josephs, O., O'Doherty, J., ZANINI, S., DEwAR, B.-K., ET AL. (2003). Human cingulate cortex and autonomic control: Converging neuroimaging and clinical evidence. Brain, 126, 2139-2152.

Damasio, A. R., \& Van Hoesen, G. W. (1983). Emotional disturbances associated with focal lesions of the limbic frontal lobe. In K. M. Heilman \& P. Satz (Eds.), Neuropsychology of human emotion (pp. 85110). New York: Guilford.

de Bruijn, E. R. A., Schubotz, R. I., \& Ullsperger, M. (2007). An event-related potential study on the observation of erroneous everyday actions. Cognitive, Affective, \& Behavioral Neuroscience, 7, 278285.

EgNer, T. (2007). Congruency sequence effects and cognitive control. Cognitive, Affective, \& Behavioral Neuroscience, 7, 380-390.

Falkenstein, M., Hohnsbein, J., \& Hoormann, J. (1991). Effects of cross-modal divided attention on late ERP components: II. Error processing in choice reaction tasks. Electroencephalography \& Clinical Neurophysiology, 78, 447-455.

Fellows, L. K., \& FARAH, M. J. (2005). Is anterior cingulate cortex necessary for cognitive control? Brain, 128, 788-796.

Forstmann, B. U., Ridderinkhof, K. R., Kaiser, J., \& Bledowski, C. (2007). At your own peril: An ERP study of voluntary task set selection processes in the medial frontal cortex. Cognitive, Affective, \& Behavioral Neuroscience, 7, 286-296.

Frank, M. J., D'Lauro, C., \& Curran, T. (2007). Cross-task individual differences in error processing: Neural, electrophysiological, and genetic components. Cognitive, Affective, \& Behavioral Neuroscience, 7, 297-308.

GABriel, M. (1993). Discriminative avoidance learning: A model system. In B. A. Vogt \& M. Gabriel (Eds.), Neurobiology of cingulate cortex and limbic thalamus: A comprehensive handbook (pp. 478523). Boston: Birkhäuser.

Gehring, W. J., Goss, B., Coles, M. G. H., Meyer, D. E., \& Donchin, E. (1993). A neural system for error detection and compensation. Psychological Science, 4, 385-390.

Gemba, H., Sasaki, K., \& Brooks, V. B. (1986). "Error" potentials in limbic cortex (anterior cingulate area 24) of monkeys during motor learning. Neuroscience Letters, 70, 223-227.

Harris, L. T., McClure, S., VAn den Bos, W., Cohen, J., \& Fiske, S. T. (2007). Regions of MPFC differentially tuned to social and nonsocial affective evaluation. Cognitive, Affective, \& Behavioral Neuroscience, 7, 309-316.

Hester, R., Barre, N., Mattingley, J. B., Foxe, J. J., \& Garavan, H. (2007). Avoiding another mistake: Error and posterror neural activity associated with adaptive posterror behavior change. Cognitive, Affective, \& Behavioral Neuroscience, 7, 317-326.

Holroyd, C. B., \& Coles, M. G. H. (2002). The neural basis of human error processing: Reinforcement learning, dopamine, and the errorrelated negativity. Psychological Review, 109, 679-709.

Holroyd, C. B., Yeung, N., Coles, M. G. H., \& Cohen, J. D. (2005). A mechanism for error detection in speeded response time tasks. Journal of Experimental Psychology: General, 134, 163-191.

Ito, S., Stuphorn, V., Brown, J. W., \& Schall, J. D. (2003). Performance monitoring by the anterior cingulate cortex during saccade countermanding. Science, 302, 120-122.

Magno, E., Foxe, J. J., Molholm, S., Robertson, I. H., \& Garavan, H. (2006). The anterior cingulate and error avoidance. Journal of Neuroscience, 26, 4769-4773.

Matsumoto, K., Suzuki, W., \& TAnaKa, K. (2003). Neuronal correlates of goal-based motor selection in the prefrontal cortex. Science, 301, 229-232.

Mayr, U., Awh, E., \& Laurey, P. (2003). Conflict adaptation effects in the absence of executive control. Nature Neuroscience, 6, 450-452.

Mesulam, M. M. (1981). A cortical network for directed attention and unilateral neglect. Annals of Neurology, 10, 309-325.

Nachev, P. (2006). Cognition and medial frontal cortex in health and disease. Current Opinion in Neurology, 19, 586-592.

Nieuwenhuis, S., Yeung, N., van Den Wildenberg, W., \& RidDERINKHOF, K. R. (2003). Electrophysiological correlates of anterior cingulate function in a go/no-go task: Effects of response conflict and trial type frequency. Cognitive, Affective, \& Behavioral Neuroscience, 3, 17-26.

Niki, H., \& Watanabe, M. (1979). Prefrontal and cingulate unit activity during timing behavior in the monkey. Brain Research, 171, 213-224.

Overbeek, T. J. M., Nieuwenhuis, S., \& RidderinkHof, K. R. (2005). Dissociable components of error processing: On the functional significance of the Pe vis-à-vis the ERN/Ne. Journal of Psychophysiology, 19, 319-329.

Paus, T., Koski, L., Caramanos, Z., \& Westbury, C. (1998). Regional differences in the effects of task difficulty and motor output on blood flow response in the human anterior cingulate cortex: A review of 107 PET activation studies. NeuroReport, 9, R37-R47.

Posner, M. I., \& DiGirolamo, G. J. (1998). Executive attention: Conflict, target detection, and cognitive control. In R. Parasuraman (Ed.), The attentive brain (pp. 401-423). Cambridge, MA: MIT Press, Bradford Books.

Posner, M. I., \& Petersen, S. E. (1990). The attention system of the human brain. Annual Review of Neuroscience, 13, 25-42.

Posner, M. I., Rothbart, M. K., Sheese, B. E., \& TAng, Y. (2007). The anterior cingulate gyrus and the mechanism of self-regulation. Cognitive, Affective, \& Behavioral Neuroscience, 7, 391-395.

RidderinkHof, K. R., Nieuwenhuis, S., \& Bashore, T. R. (2003). Errors are foreshadowed in brain potentials associated with action monitoring in cingulate cortex in humans. Neuroscience Letters, 348, 1-4.

Ridderinkhof, K. R., Ullsperger, M., Crone, E. A., \& NieuwenHUIS, S. (2004). The role of the medial frontal cortex in cognitive control. Science, 306, 443-447.

Ridderinkhof, K. R., van den Wildenberg, W. P. M., Segalowitz, S. J., \& CARTER, C. S. (2004). Neurocognitive mechanisms of cognitive control: The role of prefrontal cortex in action selection, response inhibition, performance monitoring, and reward-based learning. Brain \& Cognition, 56, 129-140.

Roelofs, A., van Turennout, M., \& Coles, M. G. H. (2006). Anterior cingulate cortex activity can be independent of response conflict in Stroop-like tasks. Proceedings of the National Academy of Sciences, 103, 13884-13889.

Rushworth, M. F., Buckley, M. J., Behrens, T. E., Walton, M. E., \& Bannerman, D. M. (2007). Functional organization of the medial frontal cortex. Current Opinion in Neurobiology, 17, 220-227.

Rushworth, M. F., Walton, M. E., Kennerley, S. W., \& BannerMAN, D. M. (2004). Action sets and decisions in medial frontal cortex. Trends in Cognitive Sciences, 8, 410-417.

Sallet, J., Quilodran, R., Rothé, M., Vezoli, J., JosePh, J.-P., \& ProCYK, E. (2007). Expectations, gains, and losses in the anterior cingulate cortex. Cognitive, Affective, \& Behavioral Neuroscience, 7, 327-336.

Schall, J. D., \& Boucher, L. (2007). Executive control of gaze by the frontal lobes. Cognitive, Affective, \& Behavioral Neuroscience, 7, 396-412.

Shima, K., \& TAnJI, J. (1998). Role for cingulate motor area cells in voluntary movement selection based on reward. Science, 282, $1335-1338$.

Stuphorn, V., \& Schall, J. D. (2006). Executive control of counter- 
manding saccades by the supplementary eye field. Nature Neuroscience, 9, 925-931.

Stuphorn, V., TaYlor, T. L., \& Schall, J. D. (2000). Performance monitoring by the supplementary eye field. Nature, 408, 857-860.

Swick, D., \& Turken, A. U. (2002). Dissociation between conflict detection and error monitoring in the human anterior cingulate cortex. Proceedings of the National Academy of Sciences, 99, 16354-16359.

van den Bos, W., McClure, S. M., Harris, L. T., Fiske, S. T., \& Cohen, J. D. (2007). Dissociating affective evaluation and social cognitive processes in the ventral medial prefrontal cortex. Cognitive, Affective, \& Behavioral Neuroscience, 7, 337-346.

Vogt, B. A., Finch, D. M., \& Olson, C. R. (1992). Functional heterogeneity in cingulate cortex: The anterior executive and posterior evaluative regions. Cerebral Cortex, 2, 435-443.

Volz, K. G., Schubotz, R. I., \& von Cramon, D. Y. (2006). Decision-making and the frontal lobes. Current Opinion in Neurology, 19, 401-406.

Walton, M. E., \& Mars, R. B. (2007). Probing human and monkey anterior cingulate cortex in variable environments. Cognitive, Affective, \& Behavioral Neuroscience, 7, 413-422.

Yeung, N., Botvinick, M. M., \& Cohen, J. D. (2004). The neural basis of error detection: conflict monitoring and the error-related negativity Psychological Review, 111, 931-959.

Yeung, N., Ralph, J., \& Nieuwenhuis, S. (2007). Drink alcohol and dim the lights: The impact of cognitive deficits on medial frontal cortex function. Cognitive, Affective, \& Behavioral Neuroscience, 7, 347-355.

\section{NOTES}

1. Interestingly, there is no verified provenance of this quotation actually being Chinese in origin. Much of its usage can probably be traced back to an address given by Robert F. Kennedy in Cape Town, South Africa, in 1966. See en.wikipedia.org/wiki/May_you_live_in_interesting_times.

2. It is because of the controversies associated with terminology, along with the increased interest in a broader set of MFC subdivisions beyond the ACC, that we have adopted the more inclusive, but also more imprecise, label of MFC to discuss the brain region that is the focus of this special issue.

3. The conference was made possible by financial support from the EPOS graduate school, the Netherlands Organization for Scientific Research (NWO), and the Amsterdam Center for the Study of Adaptive Control in Brain and Behavior (Acacia). 